\title{
Reformas do ensino básico: tendências e limites
}

Alberto de Mello e Souza*

Marly de Abreu Costa**

\section{Resumo}

0 artigo discute as reformas educacionais de terceira geração, vistas como necessárias para superar os resultados adversos do ensino básico. Inicialmente, descreve as reformas de primeira e de segunda gerações, relacionadas, respectivamente, com a qualidade dos insumos e com a questão federativa. As reformas de terceira geração buscam ampliar os incentivos que favorecem melhores resultados das escolas e se situam em duas vertentes. A primeira vertente mantém a gestão da escola e o financiamento públicos, ao passo que na segunda vertente há alguma forma de privatização. 0 trabalho conclui que existe um leque de mudanças que evita a privatização e proporciona resultados desejáveis.

Palavras-chave: Reformas educacionais. Ensino básico. Gestão educacional. Privatização.

\section{Elementary education reform: trends and limits \\ Abstract}

The discussion of third generation educational reforms, seen as required to overcome the poor results of primary education, is the main concern of this work. Initially, it describes the reforms of the first and second generations, related, respectively, to the quality of the inputs and to federal matters. The reforms of the third generation seeks to increase the incentives for the schoolwork. However, some proposals require some form of privatization. Thus, emphasis is placed upon the proposal which keeps privatization away and offers conditions to improve the performance of primary education. Keywords: Educational reforms. Primary education. School management. Privatization

Doutor em Economia, Universidade de Michigan; Professor, Faculdade de Ciências Econômicas, Universidade do Estado do Rio de Janeiro (UERJ). E-mail: amello@openlink.com.br

.. Doutora em Educação pela Universidade Federal do Rio de Janeiro (UFRJ); Professora, Faculdade de Educação, Universidade do Estado do Rio de Janeiro. E-mail: marlybreu@gmail.com

Ensaio: aval. pol. públ. Educ., Rio de Janeiro, v. 17, n. 64, p. 477-494, jul./set. 2009 


\section{Reformas en la enseñanza básica: tendencias y limites Resumen}

Este artículo plantea una discusión sobre las reformas de educación de tercera generación, que se consideran necesarias para superar los resultados adversos en la enseñanza básica. Comienza con la descripción de las reformas de primera y segunda generación, relacionadas respectivamente con la calidad de los insumos escolares y con la cuestión federativa. Las reformas de tercera generación tienen la finalidad de ampliar los incentivos que favorecen la mejora de los resultados en las escuelas y se sitúan en dos vertientes. La primera de ellas mantiene la gestión de la escuela y la financiación públicas, mientras que en la segunda existe alguna forma de privatización. El trabajo Ilega a la conclusión de que existe un abanico de cambios que evitan la privatización y proporcionan resultados deseables.

Palabras clave: Reformas de educación. Enseñanza básica. Gestión educacional. Privatización

\section{Introdução}

0 artigo tem como propósito discutir as reformas educacionais que se fazem necessárias para superar os resultados adversos do ensino básico, revelados pela baixa proficiência dos alunos e por outros indicadores educacionais, como a taxa de repetência. A discussão aborda a complexidade crescente das reformas para, em seguida, apresentar as duas vertentes ligadas à terceira geração de reformas.

As reformas educacionais podem ocorrer num plano micro, afetando um pequeno grupo de escolas, ou em sistemas educacionais. Nesta discussão, estamos interessados em reformas de âmbito nacional, geralmente definidas e estimuladas pelo Governo Federal. Essas reformas visam a alterar a concepção e a organização do trabalho escolar, ampliar os recursos educacionais e redefinir regras institucionais e mecanismos de gestão. 0 processo de reformas é desencadeado através de legislação e normas nacionais, acompanhadas pela criação e reformulação de órgãos, disponibilidade de novos recursos e a melhoria dos sistemas de informações, necessária para a construção de indicadores educacionais, capazes de aferir os resultados conseguidos.

Muitas vezes, a avaliação das reformas fica prejudicada devido às dificuldades de controlar os fatores intervenientes ou de dispor de medidas capazes de revelar 0 impacto dessas reformas em seus beneficiários finais. Além disso, atrasos e descontinuidades administrativas dificultam a percepção dos acontecimentos e nem sempre é possivel dimensionar as ações realizadas. Também, existem situações onde a resistência corporativa, o baixo envolvimento das pessoas com as mudanças e a reduzida capacidade institucional limitam, de forma silenciosa, as suas consequên- 
cias. Finalmente, a difusão e o impacto das reformas sobre as escolas estão longe de ser uniformes, atingindo primeiro e com mais intensidade, por exemplo, as escolas urbanas e, posteriormente, as escolas rurais.

A abordagem das reformas educacionais aqui seguida define uma tipologia que reflete de um lado os aspectos simultâneos e interligados de algumas medidas e, do outro, a sequência dos eventos que caracteriza as diferentes gerações. As reformas educacionais do ensino básico podem ser agrupadas em três gerações, caracterizadas por objetivos distintos. Além desta introdução, o trabalho contém cinco seções. $\mathrm{Na}$ seção seguinte são discutidas as reformas de primeira e de segunda gerações. $\mathrm{Na}$ terceira seção, são identificados os problemas críticos da escola pública. A próxima seção caracteriza as duas vertentes da terceira geração de reformas, baseadas em lógicas distintas: a da competitividade interna que busca superar a inércia e a burocracia através de mecanismos de estímulos dirigidos principalmente aos professores e a da competitividade externa das escolas, relacionada com a escolha das escolas pelos alunos e algum tipo de privatização. Finalmente, a conclusão destaca alguns pontos da discussão.

\section{Reformas de primeira e segunda gerações}

0 traço dominante da primeira geração de reformas é o de buscar suprir a escola com os recursos indispensáveis ao seu funcionamento e de assegurar um padrão de qualidade capaz de propiciar o domínio da escrita, da leitura e da aritmética nas séries iniciais. Esses recursos referem-se principalmente ao professor qualificado, à produção e distribuição do livro didático aos alunos e à existência de prédios confortáveis e de equipamentos escolares. Deveríamos também mencionar a merenda escolar e o transporte escolar, acessórios importantes para a escola. A merenda escolar beneficia, há anos, praticamente todos os alunos necessitados. A oferta de transporte escolar está crescendo, principalmente na zona rural; na zona urbana, é comum haver o passe escolar.

É fácil verificar a execução dessas reformas. Basta ver se a proporção dos professores leigos está caindo, se os livros didáticos chegam em número adequado à escola e se os programas que asseguram à escola um padrão mínimo de seus equipamentos escolares estão sendo implementados. A lógica é simples: dotar a escola com recursos adequados, tudo o mais constante, leva a uma melhoria da aprendizagem nas séries iniciais.

Mas constata-se, entre outros, que: a) o professor não faz o melhor uso do tempo em sala de aula por limitações metodológicas; b) os pais dos alunos não participam, como devem, nas atividades escolares; e c) o processo decisório da escola é afetado pelas restrições burocráticas. Ou seja, percebe-se logo que existem outros impedimentos ao bom funcionamento das escolas e que melhores resultados frequentemente estão associados a uma gestão mais efetiva e ao nivel socioeconômico dos alunos.

Ensaio: aval. pol. públ. Educ., Rio de Janeiro, v. 17, n. 64, p. 477-494, jul./set. 2009 
0 importante a assinalar é que as reformas da primeira geração podem mudar drasticamente as condições de ensino, como sugere Heyneman (2005), ao passarem do nível $\mathrm{A}$ para o nível $\mathrm{C}$, penúltimo nível na escala de qualidade da educação. Neste nível, correspondem gastos não-salariais quarenta vezes maiores do que no primeiro nível, o que se reflete na maior disponibilidade e variedade do livro didático, com repercussões importantes sobre o trabalho do professor na sala de aula.

Essas reformas não são polêmicas. Às vezes, vêm acompanhadas de maior autonomia da escola. $E$, buscam também reduzir a heterogeneidade das escolas públicas. 0 que se questiona é a falta de capilaridade, evidenciada pela lentidão para beneficiar as escolas rurais, especialmente no Nordeste. Outro exemplo de fracasso, que perdurou por muito tempo, é a falta de livros didáticos no ensino médio. Mas a redução do número de professores leigos e a oferta de livro didático no ensino fundamental são aspectos positivos. Resta a questão dos prédios e instalações escolares. Frequentemente usados de forma intensiva e partilhada pelas redes municipal e estadual e abrigando níveis de ensino diferentes, a solução desses problemas, por envolver o dualismo das redes, caberia à segunda geração de reformas.

Estas reformas lidam com o impacto educacional da questão federativa em duas linhas principais: uma maior equidade na distribuição dos recursos entre as redes estadual e municipais e a definição dos papéis e responsabilidades educacionais dos entes federativos relativos aos níveis do ensino básico. 0 Fundo de Manutenção e Desenvolvimento do Ensino Fundamental e de Valorização do Magistério (FUNDEF), desde 1998, redistribui os recursos de um fundo constituído por uma cesta de impostos. 0 sucesso do FUNDEF é devido a duas características. Primeira, sua natureza automática, devido ao uso de regras bem definidas sobre as fontes de recursos que constituem o fundo. Segunda, sua finalidade redistributiva, assegurada pela distribuição dos recursos do fundo entre o estado e os municípios de maneira proporcional ao número das matrículas no ensino fundamental e complementada pelo papel compensatório da União'

Os impactos do padrão de gastos do FUNDEF podem ser assim descritos: a) favorecimento da expansão das matrículas do ensino fundamental; b) melhoria salarial de professores nos municípios mais pobres; e c) redefinição progressiva das redes, com a municipalização crescente do ensino fundamental. Essa redefinição ainda enfrenta muitos desafios e merece maior atenção².

\footnotetext{
1 As maiores críticas ao FUNDEF são relativas a aspectos operacionais: matriculas inexistentes e dificuldades e controle dos gastos educacionais.

2 Uma discussão dos problemas da descentralização educacional no início da década de 90 é apresentada em Mello e Souza (1995).
}

Ensaio: aval. pol. públ. Educ., Rio de Janeiro, v. 17, n. 64, p. 477-494, jul./set. 2009 
Existem redes municipais com escolas de ensino médio, assim como matrículas estaduais no ensino fundamental ${ }^{3}$. Essa situação é vista como anômala e temporária; a falta de um amplo esforço de racionalização a torna permanente. Os efeitos são um número maior de turnos nas escolas que deveriam abrigar apenas uma rede e, preferencialmente, um único turno, e uma sobrecarga na gestão de alunos e professores que deveriam estar em outra rede.

A definição dos sistemas educacionais de estados e municipios pela Lei no. 9.394 (BRASIL, 1996), Lei de Diretrizes e Bases da Educação Nacional (LDB), encontra muitas dificuldades para ser atendida. 0 segundo segmento do ensino fundamental assemelha-se mais à organização do ensino médio, por disciplinas, do que à do primeiro segmento, onde um professor atua em cada turma. Isto cria uma resistência dos municípios em assumi-lo. E em numerosos casos, os municípios têm uma reduzida capacidade de gestão, relacionada com o baixo Índice de Desenvolvimento Humano (IDH) e agravada pela baixa densidade populacional.

Deve-se reconhecer que a rápida expansão recente das matrículas dificultou os esforços para reordenar os sistemas educacionais e, desta forma, permitir que usufruissem as vantagens da especialização. As escolas passaram a conviver com mais turnos e muitas serviam às duas redes, estadual e municipal, para atender às pressões da demanda. A oferta de vagas no ensino médio noturno, por exemplo, pode refletir a falta de vagas no turno diurno. Neste caso, muitos alunos que poderiam cursar o turno diurno, onde a qualidade do ensino é maior, são forçados a cursar o período noturno ${ }^{4}$.

0 fato de as escolas atenderem a alunos das duas redes gera uma indefinição das responsabilidades de cada rede pela manutenção e construção de novas escolas 5 . Nestas circunstâncias, fica difícil reduzir o número de turnos das escolas e ampliar a carga horária para um mínimo de cinco horas diárias. Essa redução, ao separar o ensino médio do fundamental, assegura que os equipamentos escolares sejam mais adequados ao biótipo dos alunos e que os laboratórios de informática e ciências, bem como a biblioteca, sejam voltados para atender a um nivel de ensino específico.

Sabe-se que as novas coortes nas faixas etárias de 7-14 anos e 15-17 anos são menores, refletindo uma queda da população jovem. A correção do fluxo em consequência da redução prevista na taxa de repetência também atua na direção de reduzir o número de vagas necessário. Como, atualmente, a taxa de escolarização

\footnotetext{
3 A questão dos contratos de trabalho dos professores também merece atenção, por haver discrepância do tratamento em redes diferentes. Mas seus efeitos sobre a qualidade do ensino parecem ser menores do que o congestionamento das escolas e não serão discutidos aqui.

4 Ver a respeito, Mello e Souza e outros (2007).

50 FUNDEF desconsidera o número de horas que o aluno passa na escola, o que estimula o uso intensivo das escolas. Os sistemas educacionais que investem em melhores escolas e na redução do número de turnos nada recebem a mais do FUNDEF, criando uma distorção.
}

Ensaio: aval. pol. públ. Educ., Rio de Janeiro, v. 17, n. 64, p. 477-494, jul./set. 2009 
líquida no ensino fundamental está próxima de $100 \%$, pode-se afirmar que, em muitos casos, não haverá necessidade de construir escolas. Já no ensino médio a expansão da demanda deve pressionar por algum tempo a expansão da rede, pois a taxa líquida de escolarização é inferior a 50\%.

Portanto, a maioria dos investimentos em novas escolas do ensino fundamental será para descongestionar as escolas existentes. No ensino médio, a essas necessidades se soma a expansão das matrículas, exigindo investimentos pesados em prédios escolares e equipamentos. No entanto, a convergência das taxas de escolarização líquida e bruta atua no sentido oposto, reduzindo a necessidade de expandir as matrículas.

Uma questão merecedora de atenção diz respeito à atrofia do papel dos estados no desenvolvimento de políticas voltadas para a qualidade do ensino, ligada ao número insuficiente de profissionais especializados. Existem três funções que cabem ao estado executar e que devem beneficiar indistintamente as escolas públicas. Estas funções são interligadas, gerando uma sinergia que aumenta as repercussões desejáveis sobre a qualidade do ensino.

A primeira função é a de interpretar e disseminar os resultados das avaliações de escolas, como o Sistema de Avaliação da Educação Básica (SAEB) e a Prova Brasil. Esta avaliação leva a constatações em, pelo menos, duas áreas importantes: as deficiências de aprendizagem de temas especificos dos currículos e a identificação de escolas com uma proficiência média baixa. No primeiro caso, as medidas corretivas abrangem a capacitação de professores e o ajuste nos currículos que considere formas de raciocínio adequadas ao desenvolvimento mental dos alunos.

No segundo caso, a função de supervisão escolar, entendida como o apoio do estado às necessidades da escola, percebidas através de visitas e de diagnósticos, é particularmente útil. Esta função já foi exercida pelo governo federal, mas acabou relegada a uma virtual extinção pelo estado. Atualmente, a maior autonomia da escola convive com o distanciamento da secretaria estadual de educação, o que prejudica especialmente as piores escolas.

A terceira função refere-se à formação inicial e continuada do professor. Os estados são os maiores empregadores de professores provenientes das licenciaturas e, como tal, deveriam exercer uma influência sobre, principalmente, as universidades públicas, buscando atualizar os conteúdos curriculares. Igualmente, deveriam oferecer estágios em escolas públicas aos licenciandos, com o objetivo de adaptálos às condições de trabalho existentes nestas escolas. Já a formação continuada do professor seria focada nos aspectos curriculares identificados na avaliação de escolas como os mais necessitados de atenção. 
Os estados devem oferecer assistência técnica aos municipios, especialmente os municipios pequenos e pobres, com dificuldades de assumir, além da educação infantil, o primeiro segmento do ensino fundamental. Nestes casos, duas soluções merecem atenção. Primeira, a organização de um consórcio de municípios vizinhos para administrar, de forma integrada, as redes municipais sob a supervisão do estado. Segunda, uma política redistributiva dentro do estado, permitindo que municipios de baixo IDH recebam uma quota maior do FUNDEF, capaz de compensar a sua maior precariedade institucional ${ }^{6}$.

Houve uma importante recentralização em favor da União em aspectos que dizem respeito à definição dos currículos, expressa pelos Parâmetros Curriculares Nacionais (PCN) (1998), e à avaliação educacional realizada pelo SAEB, que permitiu o desenho de um quadro insatisfatório sobre o desempenho dos alunos, mostrando o despreparo das escolas para enfrentar a massificação ocorrida. Esforços também foram feitos na produção de indicadores educacionais dotados de maior precisão, que mostravam a expansão do acesso ao ensino fundamental, combinada com a elevada retenção do fluxo de estudantes.

Pode-se concluir que a realização das principais reformas de segunda geração mostra resultados desiguais. As iniciativas por parte do MEC foram bem sucedidas, como exemplificadas pelo FUNDEF e pelo SAEB, embora tenha havido áreas negligenciadas, como a da formação inicial dos professores, especialmente nas universidades federais, e áreas de sucesso limitado, como a compreensão e disseminação dos PCN. Já os estados, confrontados pela demanda do ensino médio, tiveram resultados modestos tanto na definição das responsabilidades dos sistemas educacionais, que continuam confusas, como no desenvolvimento de funções voltadas para a qualidade do ensino, ainda incipientes.

\section{Desafios atuais da escola pública}

Duas constatações sobre a escola pública podem ser feitas. Primeira, que alguns problemas nodais da educação, embora possam apresentar diferenças regionais, são comuns a praticamente todos os estados. Segunda, que a escola pública não tem mecanismos autocorretivos, capazes de atacar esses problemas. Daí a importância de formular e implantar reformas educacionais que possibilitem superar este estado de coisas. Pode-se reconhecer como estratégico o problema do fluxo escolar por duas razões. Primeira, porque o atraso escolar reduz significativamente a aprendizagem do aluno ${ }^{7}$. Segunda, porque a redução do atraso escolar permite liberar vagas e outros recursos, que podem beneficiar o processo educacional.

6 A penalização de municípios pobres, expressa pela contribuição liquida de recursos ao FUNDEF, foi constatada por Esteves (2005). 7 Os elevados efeitos do atraso no ingresso e da repetência foram constatados por Mello e Souza (2005).

Ensaio: aval. pol. públ. Educ., Rio de Janeiro, v. 17, n. 64, p. 477-494, jul./set. 2009 
No passado, para atacar o problema do fluxo, foram concebidas intervenções, como a promoção automática e a aceleração de aprendizagem. Essas intervenções se mostraram inadequadas ou insuficientes. Existe uma frouxidão no uso dos recursos destinados pela escola para a aprendizagem de seus alunos. Ou seja, independente do nível de recursos de que a escola dispõe, existe uma ineficiência sistêmica no seu uso, ligada a regras inadequadas e à gestão burocrática exercida pelas secretarias de educação.

Os desafios são grandes. No período entre 1999 e 2004, os indicadores de fluxo, como as taxas de repetência e evasão, revelam, para praticamente todo o país, uma surpreendente piora. Assim, por exemplo, a taxa de repetência para o ensino médio regular aumentou de 17,2\% em 1998 para 22,5\% em 2004. A taxa de evasão aumentou, no mesmo período, de 5,7\% para 9,6\%. Este aumento inesperado e inaceitável destas taxas acentua a urgência da discussão de reformas.

Comparações entre o ensino médio ( $3^{\mathrm{a}}$ série) público e o ensino particular, com base no SAEB 2003, mostram resultados muito superiores para este último. Assim é que a proficiência média nacional em matemática é de 265,9 no caso da escola pública, e é de 340,5 para a escola particular. Esta diferença significa que a distância da proficiência média entre a escola particular e a pública é superior a um desviopadrão desta última (MELLO E SOUZA, 2007, p. 44).

Embora uma causa destes resultados possa estar na origem social mais elevada das famílias dos alunos da escola particular, a contribuição dos fatores escolares é inegável. Esta contribuição se dá por três canais principais: a) as diferentes legislações e regras a que estão submetidas as escolas pública e particular, em especial as diferentes legislações trabalhistas; b) a maior importância da aprendizagem como objetivo central da escola particular, contrastando com objetivos mais dispersos da escola pública; e c) a quase inexistência de mecanismos corretivos na escola pública.

Nas escolas particulares existe uma constante avaliação do trabalho dos professores, bem como a possibilidade de estimular os que tenham tido uma atuação meritória e substituir professores que tenham mostrado desempenho insuficiente. Estas condições de trabalho contrastam com a autonomia restrita da escola pública e as regras mais complacentes a que estão submetidas.

Aspectos ligados ao comportamento, como assiduidade e participação, são devidamente considerados pelas escolas particulares. De grande relevo é a questão disciplinar em sala de aula, motivo de diferenças notórias entre escolas públicas e particulares. Essas diferenças resultam da diluição de responsabilidades nas escolas públicas, com repercussões indesejáveis sobre a aprendizagem de seus alunos. 
Uma das causas principais da ineficiência da escola pública reside na legislação trabalhista vigente para os professores, caracterizada por custos elevados para os estados e municípios, decorrentes da aposentadoria precoce, das licenças e faltas permitidas e de um sistema de promoções que pouco considera o desempenho do professor. Em função desses custos elevados, é comum recorrer a contratos de trabalho temporários ou deixar alunos sem professor.

A insatisfação com o exercício da profissão (ambiente de trabalho penoso e salários baixos) é refletida não apenas na atuação dos professores em sala de aula, mas na válvula de escape das faltas, que chegam a cerca de $10 \%$ dos dias de trabaIho em São Paulo (O ESTADO..., 2007). Essas faltas acarretam um elevado prejuízo em função da necessidade da contratação de professores substitutos. Outro problema notório é a insuficiência de professores. Os dados são eloquentes: no Rio de Janeiro, são 20 mil alunos sem aula. Em Pernambuco, são 100 mil crianças de 7 a 14 anos sem aula (0 GLOBO, 2007).

Deve haver clareza quanto aos objetivos centrais da escola e uma definição de responsabilidades e de cobranças. A escola pública persegue vários objetivos simultaneamente, que expressam vontades de seus constituintes, como professores, pais e alunos ou que estão definidos nas regras e orientações fixadas pela secretaria de educação. Com isto, é grande o tempo dos diretores gasto em tarefas administrativas e objetivos secundários, que não estão focados na melhoria do ensino. Na escola particular predomina o diálogo entre os pais dos alunos e a direção da escola, pouco sujeito à interferência de outros grupos e de interesses corporativos.

Outras influências positivas sobre a escola particular decorrem do ambiente de competitividade existente entre elas. Esta competitividade é por prestígio, no caso das escolas que disputam os melhores alunos através de processo seletivo, e por preenchimento das vagas, no caso das demais. É claro que a competitividade pode apresentar menor intensidade em vários casos, como o da ausência de escolas próximas. Mas sempre existe a disputa por clientela, às vezes acirrada pela queda da renda familiar. E é esta competição que assegura a existência dos mecanismos autocorretivos na escola particular. $\mathrm{Na}$ escola pública, a falta de clareza quanto aos objetivos e metas, aliada ao reduzido papel dos incentivos, sinaliza uma displicência quanto aos resultados, acentuada pela baixa autonomia.

A ineficiência da escola pública acaba por se projetar sobre a questão de recursos, toldando a visão que se tem do problema. Inicialmente, deve ficar claro que existe um deficit de recursos no ensino básico, como revelado pela relação entre 0 custo unitário do ensino superior e o custo unitário do ensino médio. Enquanto esta relação em paises da Organisation for Economic Co-operation and Development (OECD), raramente é superior a três (sendo 1,0 na França e 2,4 nos Estados Unidos), 
no Brasil é igual a dez (TAFNER, 2006). Ou seja, a duplicação dos recursos para o ensino básico apenas reduziria o hiato de recursos neste nível de ensino, comparativamente à situação existente em países da OECD.

Esses recursos não incluem aqueles destinados aos investimentos na expansão dos prédios escolares e na compra de equipamentos e laboratórios, indispensáveis para a redução do número de turnos e a ampliação da carga horária para, pelo menos, cinco horas diárias. Quando se discute eficiência, a preocupação é com 0 aumento de gastos correntes ao longo do tempo, devido a fatores como a redução do tamanho da turma e os maiores salários dos professores, cujos reflexos na proficiência dos alunos são duvidosos ${ }^{8}$.

A criação de um mecanismo autocorretivo para as escolas públicas pode ocorrer através da fixação de metas para objetivos como a redução da taxa de repetência. Essas metas podem ser definidas para cada escola, nível de ensino e, até mesmo, série. As escolas que atingirem as metas devem receber recursos adicionais. Uma fonte desses recursos poderá estar ligada aos ganhos de eficiência proporcionados pela menor repetência. Mais difícil é estabelecer punições para as escolas incapazes de atingirem um patamar mínimo. Uma possibilidade é a substituição da diretoria por medida administrativa.

Outras reformas devem lidar com os problemas da legislação de pessoal, que hoje produz uma entropia considerável. Salários mais elevados terão de ser combinados, entre outros, com a avaliação dos professores e a obtenção das metas pela escola. Ou seja, haverá estímulos e prêmios associados à ideia de excelência.

\section{Vertentes da terceira geração de reformas}

A terceira geração de reformas enfrenta os fracassos de um sistema de educação de massas, acreditando que, por mais complexos que sejam os problemas, podem ser enfrentados por comportamentos favorecidos por estímulos corretos. A atuação da escola pública é vista como contraproducente, principalmente porque a gestão escolar não consegue induzir e motivar as pessoas a executarem as tarefas necessárias na forma desejável.

E a razão deste fracasso está na burocratização das relações, que valoriza a aderência a regras escritas, e na diversidade dos interesses atuantes, que resulta do controle democrático da escola pública ${ }^{9}$. Essas regras são herdadas da administração pública e impostas ao ambiente escolar, sem considerar que o trabalho do professor está pouco sujeito aos controles e, portanto, à hierarquia existente.

8 Ver, por exemplo, o debate entre Hanushek (1996), e Hedges e Greenwald (1996).

9 Sobre o contraste entre o controle democrático das escolas e a atuação do mercado, ver Chubb e Moe (1990).

Ensaio: aval. pol. públ. Educ., Rio de Janeiro, v. 17, n. 64, p. 477-494, jul./set. 2009 
Uma diferença essencial entre a escola particular e a escola pública é a atribuição das responsabilidades e das decisões. A ambiguidade e o escapismo das regras burocráticas, bem como as dificuldades de punição, solapam o exercício da autoridade no caso das escolas públicas. A consequência é que os comportamentos tendem para a mediocridade, resultando em uma baixa inovação pedagógica, já que os incentivos predominantes favorecem a preservação do status quo. 0 surgimento de um etos da escola pública mais compativel com o sucesso dos alunos parece ser o avanço que a competitividade deve trazer.

Vista desse ângulo, a questão é ampliar os incentivos que produzem os resultados desejáveis, tais como, o pagamento dos professores por mérito e sanções a comportamentos indisciplinados. Deve-se reconhecer que o trabalho na escola é limitado por vários fatores. A atuação dos professores é afetada, por exemplo, pela precariedade dos equipamentos e condições físicas da escola, por deficiências na formação inicial e por alunos com baixo nivel socioeconômico. Mesmo com a presença desses fatores, 0 desempenho da escola seria muito superior se existisse um conjunto de incentivos que focasse $o$ trabalho do professor na aprendizagem dos alunos.

Existem duas vertentes para atacar o problema. A primeira vertente busca uma maior competitividade interna ou dentro da escola ao atribuir a falta de estímulos a regras que podem ser alteradas, mesmo mantendo os recursos e a gestão na esfera pública. A lógica das reformas é de: a) conceder maior autonomia à direção, especialmente na gestão dos professores, para que a escola possa premiar e punir seus docentes; b) oferecer incentivos salariais aos professores e exigir a contrapartida da avaliação dos professores a cada quadriênio; c) estabelecer metas, que expressem a viabilidade de melhorar o ensino, criando obrigações a serem partilhadas por todos e d) ampliar as possibilidades de participação da comunidade, assegurando a transparência dos resultados dos alunos e o acesso ao processo decisório.

A segunda vertente acredita que a hierarquia e a burocracia reinantes na escola pública, o principal problema existente, são inerentes ao seu sistema político e controle democrático. Neste caso, a lógica das reformas é a de substituir essa organização da escola por outra, baseada na competitividade externa, ou seja, entre as escolas. A competitividade externa resulta do exercício pelos pais dos alunos do direito de escolher a escola para seus filhos. Este exercício gera pressões sobre as escolas, já que aquelas julgadas piores pelas famílias acabarão por perder alunos e receita. Como resposta às decisões das famílias, a direção das escolas será compelida a tomar medidas necessárias para evitar perda significativa de alunos.

Estas mudanças requerem regras mais flexiveis e maior autonomia da escola para tomar decisões em áreas como a contratação de pessoal, a escolha da metodologia do ensino e a organização curricular. A escola deixa de ser burocrática para ser

Ensaio: aval. pol. públ. Educ., Rio de Janeiro, v. 17, n. 64, p. 477-494, jul./set. 2009 
regulamentada por regras que facilitam os ajustes necessários ao cumprimento das metas. Para tal, é preciso adotar alguma forma de privatização, seja a gestão priva$\mathrm{da}$, como nas escolas charter, sejam as mudanças no mecanismo do financiamento público, que passa a beneficiar indistintamente as escolas públicas e particulares, que participam do sistema de vouchers. 0 que se quer é ampliar a influência das famílias sobre as decisões da escola.

\section{Competitividade interna e incentivos}

A competitividade interna diz respeito principalmente a melhores resultados na sala de aula através de maiores incentivos aos professores. Neste sentido, a implantação de salários competitivos, que estimulem a formação de professores mais qualificados, será inevitável. No período de ajuste às novas regras, a carência de profissionais em algumas áreas de conhecimento, como física e química, pode ser aliviada por pagamento de bônus e, até mesmo, por regras salariais distintas. Ao mesmo tempo, a direção da escola deve ter menor grau de tolerância com comportamentos inaceitáveis de professores e alunos.

Os atrativos atuais da carreira docente, como aposentadoria para as professoras aos vinte e cinco anos, estabilidade no emprego, sistema generoso de licenças e facilidade no abono de faltas, não estão ligados à atuação em sala de aula e terão de ser revistos. 0 mesmo se dá com as regras de promoção, baseadas no tempo de serviço e em diplomas de cursos universitários. Nem os anos de experiência do professor, nem seus diplomas resultam necessariamente em um melhor trabalho, expresso pela aprendizagem de seus alunos.

Uma alternativa superior seria a de premiar a atuação do professor em sala de aula, medida através dos resultados de seus alunos. A remuneração vinculada a essa atuação caracterizaria um sistema meritório. Entretanto, é difícil separar, metodologicamente, a atuação dos professores dos demais fatores que contribuem para esses resultados (HANUSHEK; RAYMOND, 2003). Ganhos salariais poderiam estar vinculados ao desempenho do professor em avaliações realizadas a cada quadriênio. Esta avaliação de professores, embora preconizada pela LDB nº 9.394 (BRASIL, 1996), ainda não foi implantada.

As escolas deveriam ter metas de desempenho, definidas por ganhos de proficiência dos alunos e por correções no fluxo escolar. Essas metas poderiam ser quadrienais, para obedecer à periodicidade bienal dos testes de proficiência. As metas seriam fixadas pela supervisão escolar, dentro de parâmetros definidos pela secretaria estadual de educação. Para a consecução dessas metas, elas devem ser desdobradas em uma série de ações executadas no dia a dia da escola, nas quais é indispensável a participação de pais e da comunidade. Os mecanismos de cobrança, tanto na esfera pedagógica como na esfera disciplinar, surgem da necessidade de atingir as metas e revelam como a competitividade interna atua.

Ensaio: aval. pol. públ. Educ., Rio de Janeiro, v. 17, n. 64, p. 477-494, jul./set. 2009 
Devido às ideias e hábitos arraigados, haverá resistências às mudanças propostas. Algumas resistências são de natureza corporativa, pois os sindicatos podem sentir-se ameaçados por uma perda de representatividade. Outras expressam a dificuldade de mudar rotinas pessoais e de aceitar novas exigências. Mudanças na legislação também podem enfrentar dificuldades no poder legislativo. Entretanto, os custos da inação se traduzem em expectativas diminuidas, cidadania enfraquecida e baixa coesão social. Estudo recente não deixa dúvidas que as escolas que adotam procedimentos como os sugeridos acima atingem melhores resultados do que as escolas tradicionais (HANUSHEK; RAYMOND, 2003).

\section{Competitividade externa, escolha de escola e privatização}

Em face de uma situação onde a escola é pesadamente burocrática e há poucas pressões para realizar um trabalho mais exigente, uma saida é oferecer aos pais dos alunos a possibilidade de escolha entre escolas. Os pais são os principais interessados (stakeholders) pela educação dos filhos, mas no sistema tradicional são poucas as oportunidades de expressar esse interesse e influenciar decisões. A escolha da escola pelos pais premia as boas escolas e coloca a necessidade das que perderam alunos de identificar e atacar os problemas. Estas pressões dependem da informação a que têm acesso os pais sobre o desempenho das escolas na vizinhança.

Deve-se entender que a possibilidade de escolha da escola está sempre ligada a uma forma de privatização. 0 conceito de privatização, quando aplicado à esfera da educação, tem duas acepções: de recursos e de gestão. Esta definição deixa de lado certas nuanças e interpretações legais, que podem ser vistas em Kemerer (2001). No primeiro caso, existe uma utilização de recursos públicos que favorece a expansão da educação particular. São exemplos bolsas de estudo e outras formas de subvenção, como a transferência de recursos públicos às escolas e os vouchers.

0 voucher é recebido pelas famílias e utilizado como pagamento em escolas públicas e particulares que participam do programa. Ao mudar o canal de distribuição de recursos públicos, estimula a competição entre escolas e amplia a escolha dos alunos (MOE, 2001). Escolas públicas e particulares podem participar, desde que sujeitas à regulamentação específica formulada pelo Estado. Essas escolas buscam um ambiente capaz de estimular decisões adequadas à solução dos problemas defrontados pelos alunos. Desta forma, é possivel focar a atenção nas ações prioritárias, ainda que resguardando princípios inegociáveis, como igualdade de acesso e gratuidade da escola pública. Uma das experiências mais antigas com o voucher é a do Chile, iniciada em 1980 (CARNOY; MCEWAN, 2001).

Outra modalidade de transferência de recursos públicos se dá através de vantagens fiscais. No caso brasileiro, pode-se mencionar a dedução do imposto de renda de uma parcela dos gastos educacionais de famílias e o abatimento de tributos

Ensaio: aval. pol. públ. Educ., Rio de Janeiro, v. 17, n. 64, p. 477-494, jul./set. 2009 
devidos pelas universidades particulares que participam do Programa Universidade para Todos (PROUNI). Nestes casos, os recursos públicos favorecem a expansão de instituições de ensino privado na medida em que os alunos tomam decisões em função dessas vantagens fiscais.

A privatização da gestão ocorre com a sua transferência para o setor privado, seja através de uma empresa, seja através de uma cooperativa ou grupo de pessoas, embora os prédios escolares e os recursos continuem públicos ${ }^{10}$. São firmados contratos, estabelecendo metas e condições a serem obedecidas pelo gestor privado.

Um exemplo desse tipo de privatização são as escolas charter, que podem tomar maiores iniciativas no campo pedagógico e na escolha dos professores, dispondo de grande autonomia em relação às autoridades locais. Essas escolas estão sujeitas à competitividade externa e devem obedecer a conceitos da educação pública, como o acesso igual para todos, sem a realização de testes, e a gratuidade plena. $\mathrm{Na}$ prática, as condições de adoção das escolas charter em quatro estados americanos variaram bastante em função da situação do legislativo, da liderança do governador e da força do sindicato dos professores (HASSEL, 1999).

Outra possibilidade, descrita na proposta de Chubb e Moe (1990), consiste na introdução do princípio da escolha em apenas escolas públicas. Neste caso, os recursos são repassados diretamente às escolas em função do número de alunos e existe uma autonomia da escola, equivalente ao que aqui foi definido como privatização da gestão (CHUBB; MOE, 1990).

A privatização substitui, em parte, o governo pelo mercado, ao assegurar o poder de escolha aos alunos e tornar a escola, financeiramente, dependente desta escolha. . A competitividade sofre restrições porque cabe ao governo, através da regulamentação das escolas e dos contratos, definir padrões de comportamento aceitáveis. No caso dos vouchers, existem regras que definem as escolas públicas e privadas que poderão ser escolhidas, como exemplificadas nos casos do Chile e de Milwaukee ${ }^{11}$. No Brasil, o PROUNI beneficia o setor privado, sob os argumentos de vagas ociosas nas universidades particulares, custos unitários baixos e abertura de oportunidades.

A importância crescente do papel da regulamentação em privatizações pode ser vista pelo voucher, concebido como uma transferência de renda modesta para ajudar as familias a escolher e pagar as escolas de sua preferência. Nesta concepção, a proposta do voucher, formulada por Milton Friedman destinava-se a favorecer o ensino particular, numa visão libertária. Posteriormente, revista por Christopher

10 Um exemplo de privatização de gestão no Brasil é o de Maringá (Paraná), cuja experiência parece ter sido positiva, embora curta. (CORRÊA, 1993).

11 Ver, respectivamente, Carnoy e Mcewan (2001), e Hess (2002).

Ensaio: aval. pol. públ. Educ., Rio de Janeiro, v. 17, n. 64, p. 477-494, jul./set. 2009 
Jencks, tornou-se uma proposta para enfrentar as deficiências da escola pública e, com forte regulamentação, beneficiar os estudantes mais necessitados. A introdução do voucher nos Estados Unidos foi em Milwaukee, em 1990. Neste caso, apenas crianças de famílias com baixa renda tinham acesso ao programa, predominantemente desenvolvido em escolas públicas ${ }^{12}$. As experiências de Milwaukee e de outras duas localidades que adotaram o voucher revelam que o impacto sobre o sistema de escolas foi amortecido por restrições de ordem prática (HESS, 2002).

Existem dois aspectos da regulamentação que merecem atenção. Para evitar a concentração de bons alunos nas melhores escolas, é definido um percentual de alunos que ingressa por sorteio ou por método semelhante. Desta forma, a qualidade da escola deixa de ser fortemente influenciada pela "autosseleção" de seus alunos. Outro aspecto diz respeito à gratuidade. Normalmente, as escolas particulares não podem cobrar de seus alunos. E para estimular a aceitação de alunos com algum deficit de aprendizagem, o valor pago à escola é aumentado.

\section{Conclusões}

Podemos distinguir três gerações de reformas. A primeira refere-se á dotação dos recursos mínimos para a escola. A segunda diz respeito à influência da federação sobre os sistemas educacionais. Ainda falta completar as reformas de segunda geração, favorecendo as funções de qualidade no âmbito dos estados, abrindo espaço para uma carga horária mínima de cinco horas diárias, definindo com clareza as responsabilidades do estado e dos municípios e melhorando a formação dos professores. 0 atraso destas reformas coloca em questão a capacidade institucional dos estados de exercerem sua liderança na solução de problemas, devido à falta de pessoal especializado e às dificuldades de negociação com os municípios. A terceira geração aborda a questão dos estímulos corretos em suas duas vertentes.

Para nossos propósitos, basta-nos reconhecer três tipos de escolas públicas ligados a políticas educacionais distintas. Primeira, a escola pública tradicional, com gestão e financiamento públicos, obedecendo a uma estrutura burocrática emanada das leis do serviço público. Segunda, a escola pública, com gestão e financiamento públicos, mas com regras flexiveis e maior autonomia na gestão. Terceira, a escola na qual o financiamento continua público, mas a distribuição desses recursos está ligada à escolha da escola pelos pais. Neste caso, a gestão pode-se tornar privada, como nas escolas charter ou os recursos públicos podem beneficiar, através dos vouchers, as escolas públicas particulares.

A defesa da escola pública tradicional utiliza, de forma predominante, a ideia de que o ensino público é uma força a favor da maior homogeneidade social e cuja responsabilidade essencial pertence ao Estado. Desta forma, também é assegurada a

12 Para uma descrição da evolução da ideia do voucher, ver Moe (2001). 
laicidade das escolas. A primeira parte deste argumento não contempla a expansão recente do ensino básico que, ao atingir o estágio da massificação, caracterizado pelo acesso universal, deixou de oferecer níveis de proficiência e de conclusão aceitáveis.

A segunda parte do argumento afirma que a escola pública deve ficar no âmbito do Estado, obedecendo ao seu ordenamento legal, que abrange a carreira do professor, as relações entre as instâncias administrativas, as regras para a gestão no âmbito escolar e os mecanismos de alocação dos recursos. A questão que se coloca é como superar os efeitos negativos, em um sistema massificado, da hierarquia e da burocracia, que causam decisões lentas e incapazes de atuar sobre os problemas defrontados pelas escolas.

Cabe entender que o papel essencial do Estado não está ligado a um tipo específico de regras burocráticas. Ao contrário, deve-se reconhecer que as mesmas regras da administração pública, quando aplicadas à escola, estão fadadas ao insucesso, posto que a aula não é comparável a uma tarefa administrativa, à qual se aplicam controles burocráticos.

Uma comparação entre as soluções que ampliam a competitividade favorece, a nosso ver, aquela aqui chamada de competitividade interna. Primeiro, a resistência às soluções que envolvem alguma forma de privatização será grande, como visto nos conflitos históricos ocorridos no contexto da discussão das reformas educacionais. Segundo, a existência da dualidade das escolas, onde convivem as redes estadual e municipais, dificulta a introdução do direito de escolha da escola, pois as duas redes podem não adotar a mesma política. Terceiro, a competitividade externa pressupõe que as escolas públicas tenham infraestrutura satisfatória e apenas um turno. No Brasil, os investimentos para recuperação e expansão da rede escolar serão elevados.

Quarto, para que a escolha de escolas gerem as pressões a serem transformadas em ações é preciso que os pais tenham ampla informação sobre as escolas e que as escolas sejam capazes de adotar os padrões desejados pelos alunos. Existe uma assimetria de informações, ou seja, quanto maior a classe social, maiores as informações disponiveis. Pode-se concluir que as melhores escolas terão os melhores alunos e as maiores pressões. Neste caso, as piores escolas de uma vizinhança não terão como competir.

No Brasil, existem possibilidades de escolha da escola, pois não há a obrigação de a escola ficar na mesma vizinhança onde reside 0 aluno. 0 que faltam são os incentivos para a escola responder às pressões, relacionados à carreira e aos salários dos professores, ao estabelecimento de metas e à maior autonomia de gestão. Estas reformas parecem ser mais fáceis de serem introduzidas diretamente nas redes estaduais e municipais do que através da criação de novas instituições ou de mudanças nos canais de financiamento. 
0 desafio das reformas é grande e seu sucesso estará ligado à aceitação pela opinião pública e pelas famílias. A questão é: se até agora pouco mudou, por que mais irá mudar no futuro? 0 cerne do problema é mudar o comportamento de alunos e professores, através de estímulos adequados. Esta é a preocupação das reformas de terceira geração.

\section{Referências}

BRASIL. Lei n. 9.394, de 20 de dezembro de 1996. Estabelece as diretrizes e bases da educação nacional. Leis, Brasília, DF, 23 dez. 1996. Disponível em: <http://www.planalto.gov.br/ CCIVIL_03/LEIS/L9394.htm>. Acesso em: 15 set. 2009.

CARNOY, M.; MCEWAN, P. J. Privatization through vouchers in developing countries: the cases of Chile and Colombia. In: LEVIN, H.M. (Ed.). Privatizing education: can the marketplace deliver choice, efficiency, equity and social cohesion? Colorado: Westview Press, 2001.

CHUBB, J. E.; MOE, T. M. Politics, markets and America's schools. Washington, DC: The Brookins Institution, 1990.

CORRÊA, V. L. A. Avaliação de programas educacionais. a experiência das escolas cooperativas em Maringá (PR). 1993. Dissertação (Mestrado) - Escola Brasileira de Administração Pública, Fundação Getúlio Vargas, Rio de Janeiro, 1993.

0 ESTADO DE SÃO PAULO, São Paulo, p. A-26-27, 15 abr. 2007.

ESTEVES, L. C. G. FUNDEF no Rio de Janeiro: a ótica dos perdedores. 2005. Tese (Doutorado) - Faculdade de Educação, Universidade Federal do Rio de Janeiro, Rio de Janeiro, 2005.

O GLOBO, Rio de Janeiro, p. 3-4-8, 15 abr. 2007.

HANUSHEK, E. A. School resources and student performance. In: BURTLESS, G. (Ed.). Does money matter? the effect of school resources on school achievement and adult success. Washington, DC: Brookings Institution Press, 1996.

HANUSHEK, E. A.; RAYMOND, M. E. Lessons about the design of state accountability. In: PETERSON, P. E.; WEST, M. R. No child left behind?: the politics and practice of school accountability. Washington, DC: Brookings Institution Press, 2003. 
HASSEL, B. C. The charter schoo/ challenge: avoiding the pitfalls, fulfilling the promise. Washington, DC: Brookings Institution Press, 1999.

HEDGES, L.V. ; GREENWALD, R. Have times changed? The relation between school resources and student performance. In: BURTLESS, G. (Ed.). Does money matter? the effect of school resources on school achievement and adult success. Washington, DC: Brookings Institution Press, 1996.

HESS, F. M. Revolution at the margins. the impact of competition on urban school systems. Washington, DC: Brookings Institution Press, 2002.

HEYNEMAN, S. P. Avaliação da qualidade da educação: lições para o Brasil. In: MELLO E SOUZA, A. (Org.). Dimensões da avaliação educacional. Petrópolis, RJ: Vozes, 2005.

KEMERER, F. R. The legal status of privatization and vouchers in education. In: LEVIN, H. M. (Ed.). Privatizing education: can the marketplace deliver choice, efficiency, equity and social cohesion?. Colorado: Westview Press, 2001.

MELLO E SOUZA, A. Determinantes da aprendizagem em escolas municipais do Estado do Rio de Janeiro. Ensaio: avaliação e políticas públicas em educação, Rio de Janeiro, v.13, n. 49, out./dez. 2005. . Gestão da escola e qualidade da educação. In: VELLOSO, J. P. R.; ALBUQUERQUE, R. C.; KNOOP, J. (Coord.). Politicas sociais no Brasil: descentralização, eficiência e equidade. Rio de Janeiro: INAE: ILDES, 1995.

MELLO e SOUZA, A. et al. Ficando para trás. o ensino médio no Estado do Rio de Janeiro. São Paulo: Instituto Unibanco, 2007.

MOE, T. M. Schools, vouchers and the American public. Washington DC: Brookings Institution Press, 2001.

PARÂMETROS Curriculares Nacionais: introdução aos parâmetros curriculares nacionais. Brasilia, DF: MEC, Secretaria de Educação Fundamental, 1998.

TAFNER, P. (Ed.). Brasil: o estado de uma nação. Rio de Janeiro: IPEA, 2006.

Recebido em: 05/04/2009

Aceito para publicação em: 14/07/2009 